\title{
FAKTOR-FAKTOR YANG BERHUBUNGAN DENGAN PERSEPSI NYERI HAID PADA REMAJA PUTRI DI SMA FRATER DON BOSCO MANADO
}

\author{
Yulinda Veronica Fralya Worung ${ }^{1}$, Herlina I.S. Wungouw ${ }^{2}$, Septriani Renteng ${ }^{3}$ \\ ${ }^{1}$ Mahasiswa Program Studi Ilmu Keperawatan Fakultas Kedokteran Universitas Sam Ratulangi \\ Manado \\ ${ }^{2}$ Program Pendidikan Dokter Fakultas Kedokteran Universitas Sam Ratulangi Manado \\ ${ }^{3}$ Program Studi Ilmu Keperawatan Fakultas Kedokteran Universitas Sam Ratulangi Manado \\ Email : yulindaworung@gmail.com
}

\begin{abstract}
Menstrual pain is not dangerous but can reduce and inhibit adolescents from daily activities. Consideration for menstrual protection is needed and students must determine why they can receive menstrual care based on factors that can help them function at school and no longer need menstrual help. The purpose of this study was to identify factors associated with pain perception in young women in Don Bosco Manado High School. This research method uses a correlational research method with cross sectional study, and the test used is chi-square and then followed by Kolmogorov-Smirnov alternative trials. The sample uses the Non Probability Sampling technique, specifically the purposive sampling technique for 64 female students. The results obtained are significant values for the perception of menstrual pain as follows: correlated with age of menarche is $P$. Value $=0,000<0.05$; with a family history is $P$. Value $=0.094>0.05$; with menstrual duration is $P$. Value $=0.605<0.05$; and the stress level is $P$. Value $=0.045>0.05$. The conclusion of this study found a relationship between menarche age and stress level with the perception of menstrual pain, while family history and duration of menstruation with menstrual pain perception were not related. Suggestions, it is expected that young women can find out the causes and how to cope with menstrual pain they feel.
\end{abstract}

Keywords: factors, attitude, menstrual pain, adolescents.

\begin{abstract}
Abstrak: Nyeri haid tidak berbahaya namun bisa menurunkan dan menghambat remaja dalam melakukan aktivitas sehari-hari. Sehingga perlu adanya pencegahan dan penanganan yang tepat untuk mengurahi dampak dari nyeri haid dan para siswi harus tahu kenapa mereka bisa mendapatkan nyeri haid berdasarkan dari faktor-faktor yang diteliti agar bisa membantu mereka beraktivitas di sekolah dan tidak lagi izin karena nyeri haid. Tujuan penelitian untuk mengetahui faktor-faktor yang berhubungan dengan persepsi nyeri haid pada remaja putri di SMA Frater Don Bosco Manado. Metode yang dugunakan desain penelitian korelasional dengan pendekatan cross sectional, dan uji yang digunakan yaitu uji chi-square kemudian dilanjutkan dengan uji alternatif uji Kolmogorov-Smirnov dan Sampel penelitian ini menggunkan teknik Non probability sampling dengan teknik sampling yang digunakan purposive sampling dengan jumlah sampel 64 siswi. Hasil penelitian mendapatkan hasil pada hubungan menarche dengan persepsi nyeri haid nilai signifikan P.Value $=0,000<0,05$, pada hubungan riwayat keluarga dengan persepsi nyeri haid nilai signifikan P.Value $=0,094>0,05$, pada hubungan lama menstruasi dengan persepsi nyeri haid nilai signifikan P.Value $=0,605>$ 0,05 dan pada hubungan tingkat stres dengan persepsi nyeri haid nilai signifikan P.Value $=$ $0,045<0,05$. Kesimpulan, terdapat hubungan antara usis menarche dan tingkat stress dengan persepsi nyeri haid, sedangkan riwayat keluarga dan lama menstruasi dengan persepsi nyeri haid tidak memiliki hubungan. Saran, diharapkan kepada para remaja putri agar dapat mengetahui penyebab-penyebab dan cara mengatasi nyeri haid yang mereka rasakan.
\end{abstract}

Kata Kunci : faktor-faktor, Sikap, Nyeri Haid, Remaja. 


\section{PENDAHULUAN}

Menstruasi merupakan suatu keadaan fisiologis, tetapi bisa menimbulkan keluhan, pada saat menstruasi, sering muncul keluhan seperti nyeri perut bagian bawah, menstruasi yang tidak teratur, nyeri pinggang dan salah satunya adalah nyeri haid atau dismenore, dimana nyeri haid umumnya terjadi pada usia remaja (Sukarni dkk, 2013). Nyeri haid atau dismenore pada topik ini adalah nyeri haid berat sampai menyebabkan perempuan mengobati dirinya sendiri dengan obat anti nyeri atau mendatangi dokter (Anwar, dkk, 2011). Nyeri haid yang terjadi pada remaja menyebabkan aktivitas dan konsentrasi menjadi terganggu, selain itu pada remaja yang masih duduk di bangku sekolah yang dibebankan oleh kegiatan, pelajaran yang sulit, serta tuntutan dari sekolah, sehingga beberapa diantaranya harus izin untuk tidak masuk sekolah atau beristirahat di UKS sehingga tidak dapat mengikuti pelajaran karena nyeri haid (Kusmiran, 2011). World Health Organization (2010) mendapatkan kejadian nyeri haid sebesar 1.769 .425 jiwa $(90 \%)$ wanita yang mengalami dismenore dengan $10-15 \%$ mengalami dismenore berat. Sehingga membuat mereka tidak bisa melakukan aktivitas, sehingga menurunkan kualitas hidup dan reaksi yang dirasakan sangat bervariasi setiap wanita. Angka kejadian nyeri haid di setiap negara sangat besar sekali, menurut Lacovides (2015) dari $45 \%-95 \%$ perempuan yang menstruasi mengalami nyeri haid. sedangkan menurut Gagua (2012) di India terdapat 52,01\%. Kejadian nyeri haid di Indonesia cukup besar yaitu mencapai $50 \%-70 \%$ perempuan di Indonesia yang merasakan nyeri haid menurut Ramadani (2014). Angka kejadian nyeri haid di Manado pada tahun 2010 mencapai $98,5 \%$ pada siswi sekolah menengah pertama (Sophia Muda \& Jemadi, 2013). Studi pendahuluan pada siswi yang sudah menstruasi di SMA Frater Don Bosco Manado dilakukan pada 20 siswi $X$ IPA yang diwawancarai, dan terdapat 18 siswi (90\%) mengalami dismenore dan 2 siswi (10\%) tidak mengalami dismenore. Penanganan yang dilakukan oleh para siswi yaitu tidur, dibiarkan saja, memakai minyak kayu putih, mengonsumsi makanan, dan melakukan aktivitas. Pada kejadian nyeri haid pasti memiliki faktor yang mempengaruhi nyeri haid yang telah diidentifikasi dalam berbagai literature dengan hasil prevalensi yang sangat beragam, antara lain faktor menarche, riwayat keluarga, lama menstruasi, tingkat stres. Penelitian yang dilakukan Grandi (2012), mendapatkan bahwa wanita yang mengalami nyeri haid cenderung mengalami menstruasi lama dan menarche dini.

Nyeri haid tidak berbahaya namun bisa menurunkan dan menghambat remaja dalam melakukan aktivitas sehari-hari sehingga dapat menurunkan produktivitas remaja. Sehingga perlu adanya pencegahan dan penanganan yang tepat untuk mengurahi dampak dari nyeri haid dan para siswi harus tahu kenapa mereka bisa mendapatkan nyeri haid berdasarkan dari faktor-faktor yang diteliti dan juga sampai di skala berapa tingkat nyeri haid mereka agar bisa membantu mereka beraktivitas di sekolah dan tidak lagi izin tidak masuk kelas karena nyeri haid. Berdasarkan fenomena di atas peneliti tertarik untuk meneliti masalah tentang faktor-faktor yang berhubungan dengan persepsi nyeri haid pada remaja putri di SMA Frater Don Bosco Manado.

\section{METODE PENELITIAN}

Jenis penelitian ini adalah kuantitatif yaitu jenis penelitian yang menghasilkan penenuan-penemuan yang diperoleh menggunakan desain penelitian korelasional dengan pendekatan cross sectional dimana dalam desain ini variabel pengukurannya hanya dilakukan satu kali atau satu saat. Tempat penelitian dilakukan di SMA Frater Don Bosco Manado dilakukan pada bulan Juni 2020. Populasi yang diambil dalam penelitian ini adalah remaja putri yang mengalami menstruasi di kelas X IPA-IPS dan XI IPA-IPS yang berjumlah 64 siswi. Sampel yang digunakan dalam penelitian ini 
harus sesuai dengan kriteria yaitu siswi yang berada di kelas X dan XI IPA-IPS SMA Frater Don Bosco Manado, bersedia menjadi responden dalam penelitian, Siswi kelas X dan XI IPA-IPS SMA Frater Don Bosco Manado yang menggunakan Whatsapp atau Email yang aktif, berumur 15-17 tahun dan sedang mengalami menstruasi. Instrument dalam penelitian ini menggunakan kuisioner. Lembar kuesioner yang berisi tentang pertanyaan usia menarche, lama menstruasi, riwayat keluarga dan kuesioner tingkat stress DASS (Depressi on Anxiety Stres Scale) untuk mengetahui berapa tingkat stress yang dialami oleh remaja putri di SMA Frater Don Bosco Manado, dan untuk skor tingkat stress yaitu, 0 : Tidak ada atau tidak pernah, 1 : kadang-kadang, 2 : Sering, 3 : Sangat sesuai dengan yang dialami, atau hampir setiap saat. Dan untuk nilai tingkat stress, skor $0-14=$ normal, skor $15-18=$ ringan, skor $19-25=$ sedang, skor 26-33 = berat, skor $>34=$ sangat berat. sedangkan untuk pengukuran skala nyeri haid menggunakan Lembar pengukuran nyeri Numeric Rating Scale(NRS). Tujuannya untuk mengetahui berapa skala nyeri yang dirasakan responden ketika mengalami nyeri menstruasi. Kemudian dilakukan pengolahan data secara manual, setelah itu dimasukkan pada master tabel dan pengolahan data dilakukan analisis melalui uji statistik dengan menggunakan komputer dengan tahap-tahapan sebagai berikut Editing, Coding, Entry, dan Cleaning, yang terakhir semua data dilakukan uji univariat dan bivariat melalui SPSS.

\section{HASIL DAN PEMBAHASAN}

A. HASIL

1. Karakteristik Responden

Tabel 1.Distribusi Frekuensi Responden Menurut Usia

\begin{tabular}{lll}
\hline Usia & $\mathbf{N}$ & $\mathbf{\%}$ \\
\hline 15 & 32 & 50 \\
16 & 27 & 42,2 \\
17 & 5 & 7,8 \\
\hline Total & 64 & 100
\end{tabular}

Sumber : Data Primer, 2020
Tabel 2. Distribusi Frekuensi Responden Menurut Kelas

\begin{tabular}{lll}
\hline Kelas & $\mathbf{N}$ & $\mathbf{\%}$ \\
\hline 10 & 32 & 50 \\
11 & 32 & 50 \\
\hline Total & 64 & 100 \\
\hline
\end{tabular}

Sumber : Data Primer, 2020

\section{Analisa Univaiat}

Tabel 3. Distribusi Frekuensi Responden Berdasarkan Usia Menarche

\begin{tabular}{lll}
\hline $\begin{array}{l}\text { Usia } \\
\text { Menarche }\end{array}$ & $\mathbf{N}$ & \% \\
\hline$<12$ & 36 & 56,3 \\
$>12$ & 28 & 43,8 \\
\hline Total & 64 & 100 \\
\hline
\end{tabular}

Sumber : Data Primer, 2020

Tabel 4. Distribusi Frekuensi Responden Berdasarkan Riwayat Keluarga

\begin{tabular}{lll}
\hline $\begin{array}{l}\text { Riwayat } \\
\text { Keluarga }\end{array}$ & N & \% \\
\hline Ya & 59 & 92,2 \\
Tidak & 5 & 7,8 \\
\hline Total & 64 & 100 \\
\hline
\end{tabular}

Sumber : Data Primer, 2020

Tabel 5. Distribusi Frekuensi Responden Berdasarkan Lama Menstruasi

\begin{tabular}{lll}
\hline $\begin{array}{l}\text { Lama } \\
\text { Menstruasi }\end{array}$ & N & \% \\
\hline Normal & 62 & 96,9 \\
Tidak Normal & 2 & 3,2 \\
\hline Total & 64 & 100 \\
\hline
\end{tabular}

Sumber : Data Primer, 2020

Tabel 6. Distribusi Frekuensi Responden Berdasarkan Tingkat Stres

\begin{tabular}{lll}
\hline Tingkat Stres & $\mathbf{N}$ & $\mathbf{\%}$ \\
\hline Normal & 2 & 3,2 \\
Ringan & 1 & 1,6 \\
Sedang & 8 & 12,5 \\
Berat & 15 & 23,5 \\
Sangat Berat & 38 & 59.4 \\
\hline Total & 64 & 100 \\
\hline
\end{tabular}

Sumber : Data Primer, 2020 
Tabel 7. Distribusi Frekuensi Responden Berdasarkan Skala Nyeri Haid

\begin{tabular}{lll}
\hline $\begin{array}{l}\text { Persepsi Nyeri } \\
\text { Haid }\end{array}$ & N & \% \\
\hline Tidak Nyeri & 0 & 0 \\
Nyeri Ringan & 10 & 15,7 \\
Nyeri Sedang & 24 & 37,5 \\
Nyeri Berat & 29 & 45,4 \\
Nyeri Sangat & 1 & 1,6 \\
Berat & & \\
\hline Total & 64 & 100 \\
\hline
\end{tabular}

Sumber : Data Primer, 2020

\section{Analisa Bivariat}

Tabel 8. Distribusi responden berdasarkan faktor usia menarche dengan persepsi nyeri haid

\begin{tabular}{|c|c|c|c|c|c|c|c|c|c|}
\hline \multirow{3}{*}{$\begin{array}{c}\text { Usia } \\
\text { Menarche }\end{array}$} & \multicolumn{6}{|c|}{ Persepsi Nyeri Haid } & \multirow{3}{*}{$\mathbf{n}$} & \multirow{3}{*}{$\%$} & \multirow{3}{*}{$\begin{array}{c}P \\
\text { value }\end{array}$} \\
\hline & \multicolumn{2}{|c|}{$\begin{array}{c}\text { Nyeri } \\
\text { Ringan }\end{array}$} & \multicolumn{2}{|c|}{$\begin{array}{c}\text { Nyeri } \\
\text { Sedang } \\
\end{array}$} & \multicolumn{2}{|c|}{$\begin{array}{l}\text { Nyeri } \\
\text { Berat }\end{array}$} & & & \\
\hline & $\mathbf{n}$ & $\%$ & $\mathbf{n}$ & $\%$ & $\mathbf{n}$ & $\%$ & & & \\
\hline Dini & 10 & 15,6 & 24 & 37,5 & 2 & 3,1 & 36 & 56,3 & \\
\hline Normal & 0 & 0 & 0 & 0 & 28 & 43,8 & 28 & 43,8 & 0,000 \\
\hline $\mathbf{N}$ & 10 & 15,6 & 24 & 37,5 & 30 & 45,3 & 64 & 100 & \\
\hline
\end{tabular}

Sumber : Data Primer,2020

Tabel 9. Distribusi responden berdasarkan faktor riwayat keluarga dengan persepsi nyeri haid

\begin{tabular}{|c|c|c|c|c|c|c|c|c|c|}
\hline \multirow{3}{*}{$\begin{array}{l}\text { Riwayat } \\
\text { Keluarga }\end{array}$} & \multicolumn{6}{|c|}{ Persepsi Nyeri Haid } & \multirow{3}{*}{$\mathbf{n}$} & \multirow{3}{*}{$\%$} & \multirow{3}{*}{ Pvalue } \\
\hline & \multicolumn{2}{|c|}{$\begin{array}{c}\text { Nyeri } \\
\text { Ringan }\end{array}$} & \multicolumn{2}{|c|}{$\begin{array}{c}\text { Nyeri } \\
\text { Sedang }\end{array}$} & \multicolumn{2}{|c|}{$\begin{array}{l}\text { Nyeri } \\
\text { Berat }\end{array}$} & & & \\
\hline & $\mathbf{n}$ & $\%$ & $\mathbf{n}$ & $\%$ & $\mathbf{n}$ & $\%$ & & & \\
\hline Ya & 10 & 15,6 & 24 & 10 & 15,6 & 24 & 59 & 92,2 & \\
\hline Tidak & 0 & 0 & 0 & 0 & 0 & 0 & 5 & 7,8 & 0,094 \\
\hline $\mathbf{N}$ & 10 & 15,6 & 24 & 10 & 15,6 & 24 & 64 & 100 & \\
\hline
\end{tabular}

Sumber : Data Primer,2020

Tabel 10. Distribusi responden berdasarkan faktor Lama Menstruasi dengan persepsi nyeri haid

\begin{tabular}{|c|c|c|c|c|c|c|c|c|c|}
\hline \multirow{3}{*}{$\begin{array}{c}\text { Lama } \\
\text { Menstruasi }\end{array}$} & \multicolumn{6}{|c|}{ Persepsi Nyeri Haid } & \multirow{3}{*}{$\mathbf{N}$} & \multirow{3}{*}{$\%$} & \multirow{3}{*}{$P$ value } \\
\hline & \multicolumn{2}{|c|}{$\begin{array}{c}\text { Nyeri } \\
\text { Ringan } \\
\end{array}$} & \multicolumn{2}{|c|}{$\begin{array}{l}\text { Nyeri } \\
\text { Sedang }\end{array}$} & \multicolumn{2}{|c|}{$\begin{array}{l}\text { Nyeri } \\
\text { Berat }\end{array}$} & & & \\
\hline & $\mathbf{n}$ & $\%$ & $\mathbf{n}$ & $\mathbf{n}$ & $\%$ & $\mathbf{n}$ & & & \\
\hline Normal & 0 & 0 & 10 & 15,6 & 24 & 37,5 & 28 & 43,8 & \\
\hline $\begin{array}{c}\text { Tidak } \\
\text { Normal } \\
\end{array}$ & 0 & 0 & 0 & 0 & 0 & 0 & 2 & 3,1 & 0,605 \\
\hline $\mathbf{N}$ & 0 & 0 & 10 & 15,6 & 24 & 37,5 & 30 & 46,9 & \\
\hline
\end{tabular}

Sumber : Data Primer,2020
Tabel 11. Distribusi responden berdasarkan faktor Tingkat Stres dengan persepsi nyeri haid

\begin{tabular}{|c|c|c|c|c|c|c|c|c|c|}
\hline \multirow{3}{*}{$\begin{array}{c}\text { Tingkat } \\
\text { Stres }\end{array}$} & \multicolumn{6}{|c|}{ Persepsi Nyeri Haid } & \multirow{3}{*}{$\mathbf{n}$} & \multirow{3}{*}{$\%$} & \multirow{3}{*}{$\begin{array}{c}P \\
\text { value }\end{array}$} \\
\hline & \multicolumn{2}{|c|}{$\begin{array}{c}\text { Nyeri } \\
\text { Ringan } \\
\end{array}$} & \multicolumn{2}{|c|}{$\begin{array}{c}\text { Nyeri } \\
\text { Sedang } \\
\end{array}$} & \multicolumn{2}{|c|}{$\begin{array}{l}\text { Nyeri } \\
\text { Berat }\end{array}$} & & & \\
\hline & $\mathbf{n}$ & $\%$ & $\mathbf{n}$ & $\%$ & $\mathbf{n}$ & $\%$ & & & \\
\hline Sedang & 2 & 3.1 & 8 & 12,5 & 1 & 1,6 & 11 & 17,2 & \\
\hline Berat & 8 & 12,5 & 16 & 25 & 29 & 45,3 & 53 & 82,8 & 0,045 \\
\hline $\mathbf{N}$ & 10 & 15,6 & 24 & 37,5 & 30 & 46,9 & 64 & 100 & \\
\hline
\end{tabular}

Sumber : Data Primer,2020

\section{B. PEMBAHASAN}

\section{Karakteristik Responden}

a. Berdasarkan Usia

Berdasarkan karakteristik mayoritas usia responden adalah 15 tahun sebanyak 32 responden $(50 \%)$, responden yang berusia 16 tahun sebanyak 27 responden $(42,2 \%)$, dan usia 17 tahun sebanyak 5 responden $(7,8 \%)$ dari total 64 responden, usia pada penelitian ini sejalan dengan yang dikemukakan oleh Sarwono, 2011 yaitu batasan usia remaja Indonesia yaitu usia 1124 tahun dan belum menikah. Berdasarkan usia semua responden pada penelitian ini bisa beresiko mengalami nyeri haid. Amita et al (2010) mengemukakan pendapat bahwa sekitar 70-90\% kasus nyeri haid terjadi di usia remaja.

b. Berdasarkan Kelas

Hasil penelitian yang dilakukan terhadap 64 responden ditemukan kelas responden, terdiri dari 2 kelas yaitu kelas $\mathrm{X}$ dan XI masing-masing sebanyak 32 responden dengan presentase $(50 \%)$.

\section{Analisa Univariat}

a. Usia Menarche

Hasil penelitian didapatkan usia menarche dari 64 responden yaitu menadapatkan menarche dini sebanyak 36 responden (56,3\%), dan menarche normal sebanyak 28 responden $(43,8 \%)$, maka disimpulkan dari penelitian ini kebanyakan remaja mengalami menarche dini. Hal ini sejalan dengan penelitian yang dilakukan oleh Sari, 
(2017) tentang faktor-faktor yang berhubungan dengan kejadian dismenore di SMK Swasta Istiqlal Deli Tua Kabupaten Deli Serdang, salah satu faktornya adalah usia menarche yaitu < 12 tahun yaitu $(55,4 \%)$. Usia menarche dikelompokkan menjadi kurang dari 12 tahun tergolong cepat atau dini, 13-14 tahun tergolong normal dan lebih dari 15 tahun tergolong lama.

\section{b. Riwayat Keluarga}

Hasil penelitian didapatkan riwayat keluarga dari 64 responden yang memiliki riwayat keluarga sebanyak 59 responden $(92,2 \%)$, dan yang tidak memiliki riwayat keluarga sebanyak 5 responden $(7,8 \%)$. Dari hasil penelitian disimpulkan bahwa kebanyakan responden dalam penelitian ini memiliki riwayat keluarga sebanyak 59 responden (92,2\%). Riwayat keluarga (ibu atau saudara kandung perempuan) yang mengalami nyeri haid parah, hal ini berhubungan karena kondisi anatomi dan fisiologi seseorang pada umumnya sama dengan orang tua dan saudara-saudaranya (Ehrenthal, 2010). Hal ini sejalan dengan penelitian yang dilakukan oleh Putri (2018) di SMA Dharma Sakti Medan yang mempunyai riwayat keluarga sebanyak 40 responden $(95,2 \%)$ dan minoritas yang tidak memiliki riwayat keluarga sebanyak 2 responden $(8,4 \%)$.

\section{c. Berdasarkan Lama Menstruasi}

Hasil analisa dari lama menstruasi mendapatkan responden yang mengalami menstruasi normal sebanyak 62 responden $(96,9 \%)$ dan yang mengalami tidak normal sebanyak 2 responden $(3,2 \%)$ dari 64 responden yang masuk dalam penelitian. Hal ini tidak sejalan dengan hasil penelitian yang dilakukan oleh Tia.M (2016) bahwa lama menstruasi terbanyak ada pada lama menstruasi $>7$ hari yaitu $(69,7 \%)$ dan terendah lama menstruasi $<7$ hari yaitu (30,3\%). Lama menstruasi merupakan salah satu resiko yang bisa mengakibatkan nyeri haid, lama menstruasi yang normal yaitu 37 hari, jika lebih dari itu maka dikatakan mengalami nyeri haid lebih berat (Novia \& Puspitasari, 2011). Menurut Unsal, (2010) semakin lama menstruasi terjadi maka uterus akan sering berkontraksi, sehingga mengakibatkan banyak prostaglandin yang dikeluarkan dan meimbulkan nyeri haid.

\section{d. Berdasarkan Tingkat Stres}

Analisa dari tingkat stres responden didapatkan yang mengalami tingkat stres normal sebanyak 2 responden $(3,2 \%)$, ringan sebanyak 1 responden $(1,6 \%)$, sedang sebanyak 8 responden $(12,5 \%)$, berat sebanyak 15 responden $(23,5 \%)$ dan sangat berat sebanyak 38 responden dengan presentse $(59,4 \%)$. Maka dapat disimpulkan bahwa pada penelitian ini responden paling banyak memiliki tingkat stress sangat parah yaitu (59,4\%). Ade (2011) mengatakan bahwa pada masa remaja tingkat stres dapat di pengaruhi oleh beberapa faktor yaitu, faktor kematangan, faktor belajar, faktor kemurungan, faktor merajuk, ledakan marah dan kecenderungan untuk menangis serta pada masa ini ramaja akan merasa khawatir, gelisah dan cepat marah. Selain itu perubahan mood yang drastic pada remaja ini seringkali di karenakan beban pekerjaan rumah, pekerjaan sekolah, atau kegiatan sehari-hari dirumah apalagi dalam keadaan pandemi covid-19 yang sudah berbulan-bulan tinggal di rumah.

\section{e. Berdasarkan Persepsi Nyeri Haid}

Hasil penelitian yang didapatkan tentang Persepsi nyeri haid pada 64 responden adalah paling banyak mengalami nyeri berat sebanyak 30 responden dengan presentase $(46,9 \%)$, nyeri ringan sebanyak 10 responden $(15,7 \%)$, nyeri sedang sebanyak 24 responden $(37,5 \%)$. Dalam literatur menunjukkan bahwa efek nyeri haid dapat merugikan kinerja di sekolah dan aspek psikososial. Karena itu, remaja putri yang mengalami nyeri haid memiliki hubungan yang negatif dengan keluarga dan teman, ini juga mempengaruhi kinerja di sekolah. Gulsen Eryilmaz, (2010) melaporkan bahwa ketidakhadiran di sekolah karena nyeri haid yang parah adalah 
(52\%), sedangkan yang ringan (20\%). Nyeri haid dapat menyebabkan ketidakhadiran di sekolah, kehilangan konsentrasi saat mengikuti pelajaran, ada pun yang tertidur di jam pelajaran (Aziato, dkk, 2014).

\section{Analisa Bivariat}

a. Hubungan antara usia menarche dengan persepsi nyeri haid

Berdasarkan hasil yang didapatkan dari usia menarche dengan persepsi nyeri haid di SMA Frater Don Bosco Manado mendapatkan pada kelompok usia menarche dini sebanyak 10 responden $(15,6 \%)$ yang mengalami nyeri ringan, 24 responden $(37,5 \%)$ dengan nyeri sedang, 2 responden $(3,1 \%)$ dengan nyeri barat sedangkan pada kelompok usia menarche normal yaitu sebanyak 28 responden $(43,8 \%)$ mengalami nyeri berat. Hasil analisis statistik dengan menggunakan uji chi-square diperoleh nilai $\mathrm{p}=0,000$ yang berarti $\mathrm{p}<0,05$ sehingga dapat dikatakan bahwa usia menarche dengan persepsi nyeri haid terdapat hubungan yang signifikan. Hal ini sejalan dengan penelitian yang dilakukan oleh Amelia (2016) bahwa terdapat hubungan antara usia menarche dengan dismenore primer dengan perolehan hasil $p=0,004$ yang artinya $p<0,05$. Nyeri haid dapat dipengaruhi oleh usia wanita itu sendiri, pada usia 15-22 tahun kemungkinan banyak terjadinya nyeri haid karena statusnya yang belum menikah dan belum melakukan hubungan seksual. Bertambahnya usia maka akan semakin melebar leher rahim sehingga sekresi hormon prostaglandin akan berkurang, karena menurunnya fungsi saraf rahim akan menghilangkan nyeri haid (Novia \& Puspitasari, 2010). Hasil analisa statistik menggunakan uji chi-square didapatkan ada hubungan antara usia menarche dengan persepsi nyeri haid, hasil penelitian ini sama dengan teori yang menyatakan bahwa usia menarche yang cepat akan mengakibatkan resiko terjadinya nyeri haid (Lacovides, 2015). b. Hubungan antara riwayat keluarga dengan persepsi nyeri haid

Hasil analisa antara riwayat keluarga dengan persepsi nyeri haid didapatkan bahwa yang memiliki riwayat nyeri haid dalam keluarga, rata-rata pada saat menstruasi merasakan nyeri ringan sebanyak 10 responden $(15,6 \%)$, nyeri sedang sebanyak 24 responden (37,5\%), dan yang nyeri berat sebanyak 25 responden $(39,1 \%)$ sedangkan yang tidak memiliki riwayat nyeri haid dalam keluarga yaitu memiliki nyeri berat sebanyak 5 responden $(7,8 \%)$. Pada variabel ini tidak memenuhi syarat kalau hanya di uji menggunakan chi-square, karena nilai dari expected count melebihi (20\%) maka dilanjutkan dengan uji Kolmogorov sehingga mendapatkan nilai $\mathrm{p}=0,094$ yang artinya tidak memiliki hubungan antara riwayat keluarga dengan persepsi nyeri haid pada remaja putri di SMA Frater Don Bosco Manado. Hasil penelitian ini tidak sesuai dengan teori yang dikemukakan, karena penelitian yang didapat tidak memiliki hubungan antara kedua variabel di atas. Pada hasil penelitian dari peneliti terdahulu seperti penelitian dari Eka (2014) mendapatkan hasil terdapat hubungan antara faktor riwayat keluarga dengan dismenorea didapat nilai $\mathrm{P}=0,005(\mathrm{P}<$ 0,05) maka secara statistik terdapat hubungan yang signifikan antara faktor riwayat keluarga dengan dismenorea, pada pernelitian Eka memiliki perbedaan dengan penelitian ini, karena pada penelitian sebelumnya responden yang digunakan hanya 40 dan juga kategori yang dipakai hanya 2 kategori dalam setiap variabel sehingga tidak banyak terbagi sehingga bisa mendapatkan hubungan, sedangkan pada penelitian ini memiliki 2 dan 3 kategori pada ssat melakukan uji sehingga hasil yang di dapat bisa kemungkinan tersebar, dan penelitian ini memiliki 64 responden jadi tidak berhubungan dalam penelitian ini bisa kita lihat dan bandingkan dengan penelitian terdahulu bahwa dalam jumlah pengambilan data itu juga berpengaruh akan hasil dari penelitian tersebut. 
c. Hubungan antara lama menstruasi dengan persepsi nyeri haid

Hasil penelitian yang dilakukan mendapatkan remaja yang lama menstruasi normal paling banyak mengalami nyeri ringan, sedang dan berat sebanyak 62 responden (96,9\%), sedangkan yang mengalami lama menstruasi tidak normal sebanyak 2 responden $(3,1 \%)$ dengan skala nyeri berat. Hasil uji statistik antara lama menstruasi dengan persepsi nyeri mendapatkan nilai $\mathrm{p}=0,605$ yang artinya $\mathrm{Ho}$ diterima sehingga tidak memiliki hubungan signifikan antara lama menstruasi dengan persepsi nyeri haid. Hasil penelitian ini tidak sesuai dengan teori yang dikemukakan oleh Bobak (2012) Semakin lama menstruasi terjadi, maka semakin sering pula uterus berkontraksi sehingga timbul rasa nyeri. Pada penelitian yang dilakukan oleh Rika (2017) mendapatkan tidak adanya hubungan antara lama menstruasi dengan kejadian dismenore dengan hasil $\mathrm{p}=0,823$. Pada penelitian ini tidak terdapat hubungan karena kebanyakan responden memiliki lama menstruasi yang normal, sedangkan pada teori dikatakan seseorang yang kemungkinan besar mendapat nyeri haid mengalami lama menstruasi tidak normal.

d. Hubungan antara tingkat stress dengan persepsi nyeri haid

Penelitian ini menunjukkan bahwa hasil dari analisis mendapatkan responden yang memiliki tingkat stres sedang sebanyak 11 responden $(17,2 \%)$ dengan tingkat nyeri dirasakan antara lain nyeri ringan, sedang dan berat, sedangkan tingkat stress parah memiliki 53 responden $(82,8 \%)$ dengan tingkat nyeri dirasakan yaitu ringan, sedang dan berat. Hasil uji statistik menggunakan uji chi-square dan dilanjutkan dengan uji kolmogov dan didapatkan nilai $\mathrm{p}=0,045$ $(<0,05)$ terdapat hubungan antara tingkat stres dengan persepsi nyeri haid pada remaja putri di SMA Frater Don Boasco Manado. Penelitian ini sejalan dengan yang dilakukan oleh Melinda (2017) yang mendapatkan hasil uji statistik dengan nilai $\mathrm{p}=0,000$, maka dapat disimpulkan bahwa hubungan tingkat stres dan dismenore. Dampak dari stres beraneka ragam, dapat mempengaruhi kesehatan mental maupun fisik. Salah satu dampak dari stres terhadap kesehatan adalah dismenore. Pada penelitian yang dilakukan oleh Faramarzi dan Salmalian (2014) memiliki hubungan antara tingkat stress denga kejadia nyeri haid, maka responden yang mengalami stress beresiko 1,54 kali mengalami nyeri haid dibandingkan dengan responden yang tidak stres. Menurut peneliti meskipun hasil penelitian ini berbeda dengan teori dan penelitian terdahulu tetapi kita dapat melihat bahwa semakin berat stress yang dimiliki seseorang maka akan cenderung mengalami nyeri haid. Stress bisa disebabkan oleh banyak hal contohnya malasah prestasi akademi, masalah keluarga dan sebagainya.

\section{KESIMPULAN}

1. Terdapat hubungan yang bermakna antara usia menarche dengan persepsi nyeri pada remaja putri di SMA Frater Don Bosco Manado Pada penelitian ini usia menarche paling dominan pada usia dini.

2. Tidak terdapat hubungan yang bermakna antara riwayat keluarga dengan persepsi nyeri haid pada remaja putri di SMA Frater Don Bosco Manado. Kebanyakan responden pada penelitian ini memiliki riwayat keluarga yang mengalami nyeri haid.

3. Tidak terdapat hubungan yang bermakna antara lama menstruasi dengan persepsi nyeri haid pada remaja putri di SMA Frater Don Bosco Manado. Pada penelitian ini terdapat bahwa kebanyakan responden memiliki lama menstruasi normal dan mereka mengalami nyeri haid. .

4. Terdapat hubungan yang bermakna antara tingkat stres dengan persepsi nyeri pada remaja putri di SMA Frater Don Bosco Manado. 
DAFTAR PUSTAKA

Anwar, Mochamad. (2011). Ilmu Kebidanan. Jakarta : PT Bina Pustaka Sarwono Prawiroharjo

Angelina, dkk. (2017). Faktor-Faktor Yang Berhubungan Dengan Dismenore Pada Remaja Putri Di Sekolah Menengah Atas Kecamatan Sengah Temila Kabupaten Landak. Universitas Muhammadiyah Pontianak.

Bobak., Lowdermilk., Jensen. (2012). Buku Ajar Keperawatan Maternitas .Jakarta : EGC

Charu, S dkk. (2012). Menstrual Characteristic And Prevalence And Effect of Dysmenorrheaon Quality of Life of Medical Students. International Journal of Collaborative Research on Internal Medicine and Public Health Vol. 4 No. 4

Ehrenthal, D.B. (2010). Woment healthy menstrual disorders. USE : The American College of Physicians

Evi Susanti \& Shinta Wulandari. (2016). Faktor-Faktor Yang Berhubungan Dengan Usia Menarche Pada Siswi Kelas VIII MTsN 1 Bukittinggi. STIKes Prima Nusantara Bukittinggi

Faramarzi, M dan Hajar Salmalian. (2014). Association of Phycholigic and Nonphychologic Factros With Primary Dysmenorrhea. Iran Red Cresent Med Journal.

Gagua, Tinatin dkk. (2012). Primary Dysmenorrhea : Prevalence in Adolescent Population of Tbilisi, Georgia and Risk Factors. Journal of Tourkish-German Gynecology Association

Grandi, dkk (2012). Prevalence Of Menstrual Pain In Young Women: What Is Dysmenorrhea. Dove Medical : Press Journal of Pain Research.
Ika Novia \& Nunik Puspitasari. (2010). Mempengaruhi Kejadia Dismenore Primer.

Kusmiran, Eny. (2011). Reproduksi Remaja dan Wanita. Jakarta:Salemba Medika

Lacovides S, Ingrid A, Flona CB, (2015), What We Know About Primery Dysmenorrhea Today : A Critical Review. Human Reproduction Update.

Muntari. (2010). Hubungan Stres pada Remaja Usia 16-18 Tahun dengan Gangguan Menstruasi (Dismenore) di SMK Negeri Tambakboyo Tuban. Tuban: Stikes NU.

Patricia A. Potter \& Perry, Anne G. (2011). Buku Ajar Fundamental Keperawatan (konsep, proses, dan praktik).Jakarta : EG

Julianti \& Rahman. (2014). Faktor yang Berhubungan dengan Menarche terhadap Tingkat Kecemasan Siswi Kelas SMP N 1 Salomekko Kabupaten Bone. Jurnal Ilmiah Kesehatan Diagnosis. 5 (2)

Ramadani, A. N., (2014). Hubungan Kebiasaan Aktivitas Dengan Kejadian Dismenorea Pada Siswi di SMP N 2 Demak

Silvana, Putri Dwi, (2012), Hubungan Antara Karakteristik Individu Aktivitas Fisik Dan Konsumsi Produk Susu Dengan Dismenore Primer Pada Mahasiswi FIK Dan PKM UI Depok Tahun 2012, Universitas Indonesia, FKM UI

Sophia, F. Muda, S. Jemadi. (2013). Faktor-faktor yang berhubungan dengan dismenore pada siswi SMK Negeri $10 \quad$ Medan. Skripsi.http://repository.usu.ac.id

Sarwono. (2011). Psikologi Remaja. Edisi Revisi. Jakarta: Rajawali Pers. 